\title{
Rete middle cerebral artery anomalies: a unifying name, case series, and literature review
}

\author{
Kwang-Chun Cho, MD, Jung-Jae Kim, MD, ${ }^{2}$ Chang-Ki Jang, MD, ${ }^{2}$ Chang-Ki Hong, MD, PhD, ${ }^{2}$ \\ Jin-Yang Joo, MD, PhD, ${ }^{2}$ and Yong Bae Kim, MD, PhD² \\ ${ }^{1}$ Department of Neurosurgery, College of Medicine, Catholic Kwandong University, International St. Mary's Hospital, Incheon; \\ and ${ }^{2}$ Department of Neurosurgery, College of Medicine, Yonsei University, Gangnam Severance Hospital, Seoul, Korea
}

\begin{abstract}
OBJECTIVE Rete middle cerebral artery (MCA) is extremely rare and has not been frequently discussed. Rete MCA is a weblike anomaly of the MCA that does not coalesce and forms a prominent, large single branch from the plexiform vessels in the fetal stage. The purpose of this study was to further elucidate the clinical and radiological characteristics of patients with rete MCA.
\end{abstract}

METHODS A total of 2262 cerebral digital subtraction angiography procedures were performed on 1937 patients at the authors' institution from February 2013 to May 2017. Data analysis included age, sex, clinical symptoms, underlying diseases, coexisting cerebral arterial anomalies, and operative methods and findings.

RESULTS Rete MCAs were found in 13 patients, and the incidence of this anomaly was $0.67 \%$ (13 of 1937) in this study. Of the 13 patients, 3 had hemorrhagic strokes, 6 had ischemic strokes, and 4 had no symptoms. Eight patients underwent conservative treatment, and 5 patients underwent surgical treatment. Rete MCA is considered a congenital disease of the cerebral vasculature with the possibility of an acquired abnormality, such as an aneurysm, caused by hemodynamic stress. Although an epidemiological survey of rete MCA was not conducted, it is assumed that rete MCA has a high prevalence in Asia. Ischemic and hemorrhagic stroke events are fairly common in rete MCA.

CONCLUSIONS Clinicians should understand the radiological and clinical features of patients with rete MCA to avoid misdiagnosis and unnecessary treatment. This anomaly should be differentiated from other vascular diseases and patients presenting incidentally should be carefully monitored because of their vulnerability to both hemorrhagic and ischemic strokes.

https://thejns.org/doi/abs/10.3171/2018.2.JNS1832

KEYWORDS middle cerebral artery; MCA anomaly; twiglike MCA; rete MCA; moyamoya phenomenon; vascular disorders

$\mathrm{M}$ ANY anomalies have been reported in the intracranial arteries. However, anomalies of the middle cerebral artery (MCA) are rare. Although MCA anomalies such as accessory MCAs, duplicated MCAs, and fenestrated MCAs occur infrequently, they are well understood. Among the anomalies of the MCA, a rete MCA is extremely rare and has not been frequently discussed. This anomaly has been reported under various names, including unfused or twiglike MCA., ${ }^{1,3,15,25,26,29}$ In addition, there is not much understanding of this anomaly.
The purpose of this study was to further elucidate the clinical and radiological characteristics of patients with a rete MCA anomaly. By understanding the rete MCA anomaly, clinicians can reduce the rate of misdiagnosis and avoid needless evaluation and treatment.

\section{Methods}

The study protocol was approved by our IRB (Yonsei University College of Medicine, Gangnam Severance Hos-

ABBREVIATIONS $\mathrm{ACA}=$ anterior cerebral artery; $\mathrm{ACOA}=$ anterior communicating artery; $\mathrm{DSA}=$ digital subtraction angiography; $\mathrm{ECA}=\mathrm{external}$ carotid artery; ICA = internal carotid artery; ICH = intracerebral hemorrhage; IVH = intraventricular hemorrhage; $\mathrm{MCA}=$ middle cerebral artery; SAH = subarachnoid hemorrhage; TIA = transient ischemic attack.

SUBMITTED January 5, 2018. ACCEPTED February 23, 2018.

INCLUDE WHEN CITING Published online August 3, 2018; DOI: 10.3171/2018.2.JNS1832. 
TABLE 1. Cases of rete MCA anomalies and association with aneurysms in this study

\begin{tabular}{|c|c|c|c|c|c|c|c|c|}
\hline \multirow{2}{*}{$\begin{array}{l}\text { Patient } \\
\text { No. }\end{array}$} & \multirow{2}{*}{$\begin{array}{l}\text { Sex, Age } \\
\text { (yrs) }\end{array}$} & \multirow[b]{2}{*}{ Nationality } & \multirow[b]{2}{*}{ Presentation } & \multirow{2}{*}{$\begin{array}{c}\text { Rete } \\
\text { MCA Site }\end{array}$} & \multicolumn{3}{|c|}{ Aneurysm } & \multirow[b]{2}{*}{ Treatment } \\
\hline & & & & & No. & Location & Site & \\
\hline \multirow[t]{2}{*}{1} & \multirow[t]{2}{*}{ M, 52} & \multirow[t]{2}{*}{ Korea } & \multirow[t]{2}{*}{$\mathrm{SAH}, \mathrm{ICH}, \mathrm{IVH}$} & \multirow[t]{2}{*}{ Rt } & \multirow[t]{2}{*}{2} & $M_{1}$ & $\mathrm{Rt}$ & Clipping \\
\hline & & & & & & $M_{1}$ & Rt & Clipping \\
\hline 2 & $M, 57$ & Korea & Incidental (headache) & $\mathrm{Rt}$ & - & - & - & Conservative \\
\hline 3 & $\mathrm{M}, 73$ & Korea & Acute infarction & Rt & - & - & - & Antiplatelet agent \\
\hline 4 & $\mathrm{~F}, 63$ & Korea & TIA & $\mathrm{Lt}$ & - & - & - & Antiplatelet agent \\
\hline 5 & $\mathrm{~F}, 48$ & Korea & Incidental (meningioma) & $\mathrm{Rt}$ & 1 & $\mathrm{ACoA}$ & Rt & Clipping \\
\hline 6 & M, 25 & Korea & Incidental (headache) & $\mathrm{Rt}$ & - & - & - & Conservative \\
\hline 7 & M, 36 & Korea & $\mathrm{ICH}, \mathrm{IVH}$ & $\mathrm{Rt}$ & - & - & - & Burr hole \\
\hline 8 & $\mathrm{~F}, 30$ & Korea & Incidental (headache) & $\mathrm{Lt}$ & - & - & - & Conservative \\
\hline 9 & $F, 56$ & China & $\mathrm{ICH}$ & Rt & 2 & $M_{1}$ & Rt & Clipping \\
\hline & & & & & & ICA & $\mathrm{Lt}$ & Conservative \\
\hline 10 & $\mathrm{~F}, 26$ & Korea & TIA & $\mathrm{Rt}$ & - & - & - & Antiplatelet agent \\
\hline 11 & $F, 29$ & Korea & TIA & $\mathrm{Lt}$ & - & - & - & Antiplatelet agent \\
\hline 12 & M, 37 & Korea & Acute infarction & Rt & - & - & - & Antiplatelet agent \\
\hline 13 & $M, 61$ & Korea & Acute infarction (recurred) & $\mathrm{Rt}$ & - & - & - & Bypass \\
\hline
\end{tabular}

pital). Patient consent was waived. Between February 2013 and May 2017, 2262 cerebral digital subtraction angiography (DSA) procedures were performed in 1937 patients at our institution. Three-dimensional images were evaluated to determine if any vascular anomalies were suspected. All angiograms were reviewed by the authors at our stroke center during daily and weekly conferences. When rete MCA was suspected, the patient's information-including ethnicity, nationality, age, sex, clinical symptoms, underlying diseases, coexisting cerebral arterial anomalies, and operative methods and findings - was prospectively recorded in the databases. We retrospectively reviewed these databases.

Furthermore, by searching PubMed and MEDLINE using the keywords "twig," "unfused," "aplasia," "moyamoya phenomenon," and "middle cerebral artery," we were able to review the articles about MCA anomalies.

\section{Results}

Of the 1937 patients who underwent cerebral DSA, 13 had rete MCA anomalies. Thus, the incidence rate of rete MCA anomalies was $0.67 \%(13 / 1937)$ in this study. All patients were Asian (12 Korean, 1 Chinese). There were 7 men and 6 women, ranging in age from 25 to 73 years (mean 45.6 years). All cases of rete MCA were unilateral. Rete MCA anomalies occurred on the right side in 10 patients and on the left side in 3 patients. Three patients (27.1\%) had intracranial hemorrhage on presentation. Six patients $(46.2 \%)$ had an acute infarction or transient ischemic attack (TIA) on presentation. One patient with a meningioma on the sphenoid ridge had a rete MCA anomaly on the ipsilateral side. Patient demographics and clinical features are presented in Table 1 . Five aneurysms were found in 3 patients. Four aneurysms occurred on the ipsilateral side, and 1 aneurysm occurred contralateral to the MCA anomaly. In 1 case, the lesion suspected preoperatively to be an unruptured aneurysm was the stump of the proximal anterior cerebral artery (ACA).

\section{Illustrative Cases \\ Case 1}

A 52-year-old man presented to a local hospital with a severe headache followed by drowsiness. He was immediately transferred to our hospital. Upon arrival at our hospital, he showed no focal neurological deficits except facial palsy on the left side. The primary CT scan at our hospital showed a subarachnoid hemorrhage (SAH) on the basal cistern, an intracerebral hemorrhage (ICH) located in the right basal ganglia, and intraventricular hemorrhage (IVH; Fig. 1A). DSA was performed. The right carotid angiogram revealed plexiform vascular structures instead of a definitive proximal MCA segment. However, the distal MCA segments were intact in caliber and patency. On 3D rotational angiography, there were anomalous rete vessels filling the $\mathrm{M}_{1}$ segment. However, the possible lesion of bleeding focus was not found (Fig. 1B). Two weeks later, follow-up DSA was performed, and two small aneurysms were found near the rete (Fig. 1C).

A surgical craniotomy was performed, and the two small aneurysms were clipped. A white, cordlike, fragileappearing $\mathbf{M}_{1}$ segment was found (Fig. 1D). The patient was discharged with complete resolution of his previous symptoms.

\section{Case 5}

A 48-year-old woman with a headache underwent MRI 2 years ago at our health center. The MRI showed a small meningioma at the right sphenoid ridge (Fig. 2A). At that time, DSA revealed a rete MCA anomaly at the right $\mathrm{M}_{1}$ segment and an associated small aneurysm (Fig. 2A). On the follow-up MRI, the meningioma was found to be slightly enlarged, and we decided to perform surgical removal. DSA was examined to check for changes in the rete MCA anomaly and the associated aneurysm (Fig. 2B). For about 30 months there had been no major change in the rete MCA features or aneurysmal size and shape. Through 


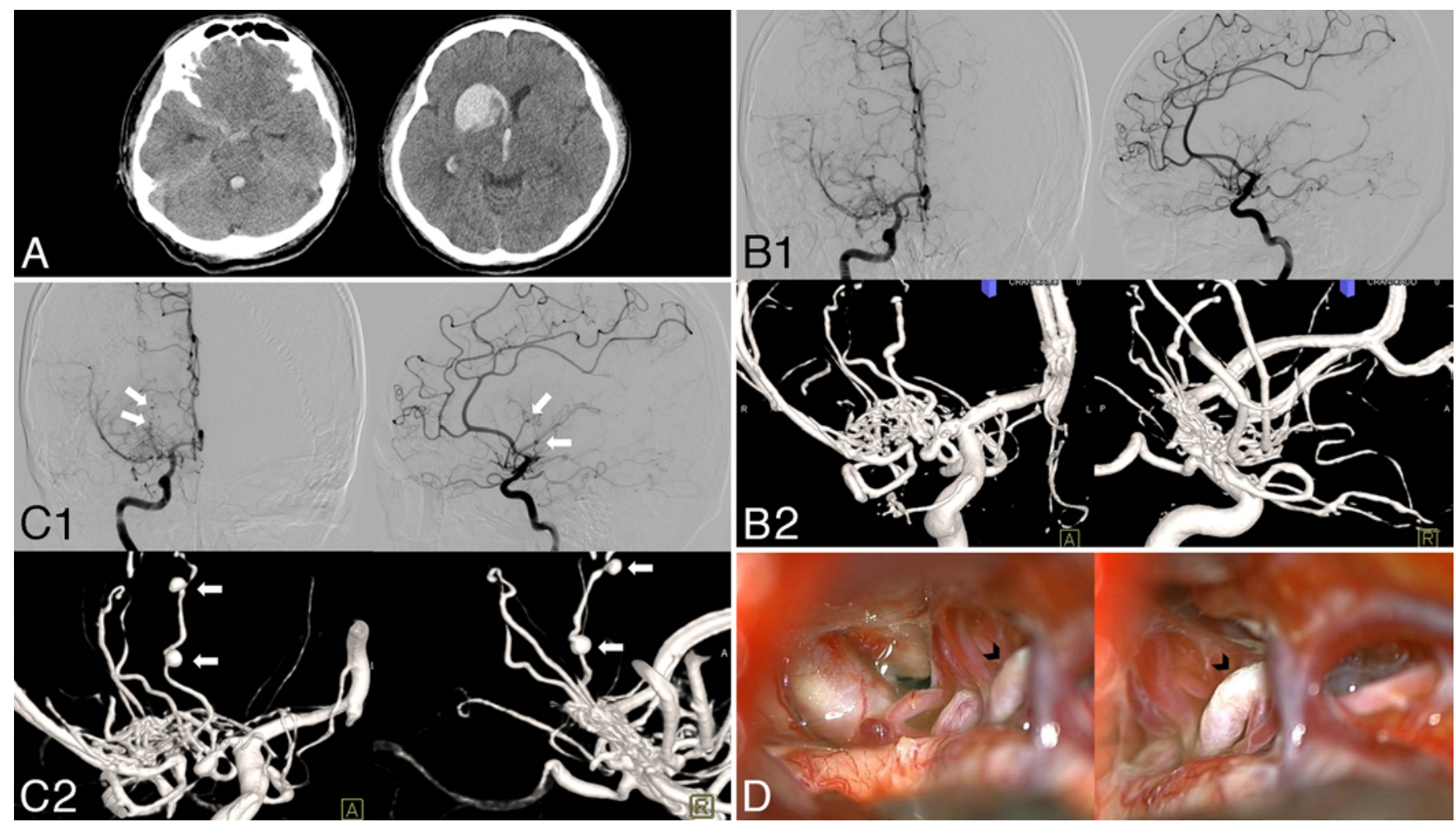

FIG. 1. Case 1. A: Initial brain CT reveals an SAH on the basal cistern, an ICH located in the right basal ganglia, and an IVH. B1 and B2: On initial DSA there is a rete MCA anomaly on the right $\mathrm{M}_{1}$ segment, but a bleeding focus, such as an aneurysm, is not noted (B1 = DSA, B2 = 3D rotational angiography). $\mathrm{C1}$ and C2: On follow-up DSA, two small aneurysms are found near the rete (arrows; $\mathrm{C} 1=\mathrm{DSA}, \mathrm{C2}=3 \mathrm{D}$ rotational angiography). $\mathrm{D}$ : The surgical field shows a white, cordlike $\mathrm{M}_{1}$ segment that appears fragile (arrowheads). Figure is available in color online only.

a pterional approach the meningioma was removed and the associated aneurysm at the anterior communicating artery (ACoA) was clipped. Surgical exploration showed atresia of the $\mathrm{M}_{1}$ segment, which exhibited a white, cordlike rudimentary appearance (Fig. 2C). Postoperative DSA showed that the aneurysm was excised after clipping the parent artery. The postoperative course was uneventful, and she was discharged with no neurological deficit.

\section{Case 9}

A 56-year-old woman with a severe headache and leftsided weakness was admitted to our hospital. Brain CT revealed an ICH in the right temporal lobe (Fig. 3A). CT angiography showed an arterial network just distal to the internal carotid artery (ICA) bifurcation. DSA revealed an $\mathrm{M}_{1}$ anomaly, and the distal MCA segments were intact in caliber and patency (Fig. 3B).

On 3D rotational angiography, the lesion was not found to be an arteriovenous malformation but a rete MCA anomaly (Fig. 3C). Additionally, one aneurysm, which we suspected was bleeding, was found inside the rete. Another aneurysm was found on the right proximal ACA. The former was clipped, and hematoma next to the aneurysm was evacuated (Fig. 3D). The latter was the stump that was linked to the vessel, which no longer had flow and was similar to a thin, white straw (Fig. 3D). The patient's hemiparesis in the left extremities improved with physical therapy, and she was discharged to a rehabilitation hospital.

\section{Discussion}

Among the various MCA anomalies, a weblike vasculature of the MCA is extremely rare and has not been frequently discussed. Although little is known about this anomaly, it has occasionally been previously reported.

\section{Various Names}

Review of the literature was complicated because of a lack of concordance in published terminology. According to the previously reported articles about MCA anomalies, the terminology "twig-like MCA" was used by Liu et al. for the first time in $2005 . .^{15}$ Separate from that study, Cekirge et al. reported a case of an MCA variation and termed it "unfused MCA" in 2005. ${ }^{3}$ However, this type of variation was previously described in several papers (Table 2). Various names have been reported, such as moyamoya-like vessel, moyamoya phenomenon, anomalous collateral artery, and aplastic MCA. Many of these papers were published in Asia, including South Korea and Japan. ${ }^{2,5,8-10,12,14,16,18,19,21,24-30}$ Therefore, for the clarity of these anomalies, we have coined the term "rete MCA anomaly" to integrate these various names. Rete means a network of blood vessels.

\section{Prevalence}

Rete MCA anomalies are very rare, and most articles reported them in the form of a case report. A few articles 

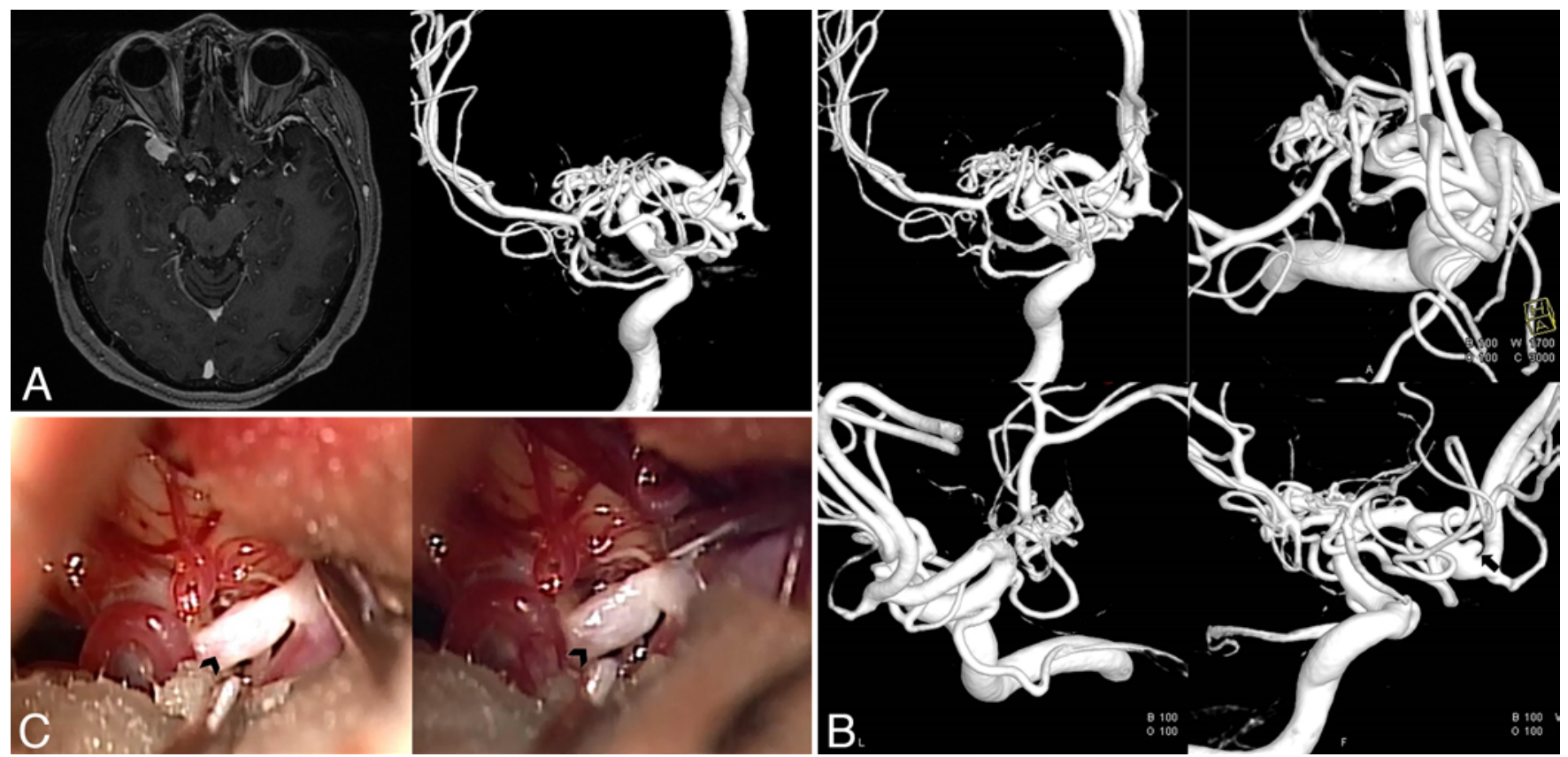

FIG. 2. Case 5. A: The MR image shows a small meningioma at the right sphenoid ridge (left). DSA (right) reveals the rete MCA anomaly at the right $\mathrm{M}_{1}$ segment and an associated small aneurysm (arrow). B: On follow-up DSA 30 months later, there is no major change in rete MCA features or aneurysmal size and shape. C: Surgical exploration shows atresia of the $\mathrm{M}_{1}$ segment, which exhibits a white, cordlike rudimentary appearance (arrowhead). Figure is available in color online only.

have examined their prevalence. The prevalence of twiglike MCA is about $0.11 \%(2 / 1814)$ according to Liu et al. ${ }^{15}$ Akkan et al. reported their experience of unfused or twiglike MCA with an incidence of $0.13 \%$ (6/4372) in their series. ${ }^{1}$ The highest frequency of aplastic or twiglike MCA was $1.17 \%(15 / 1282)$ reported by Seo et al. ${ }^{25}$ In our study, the prevalence of rete MCA was $0.67 \%$ (13/1937) by angiographic examination. This prevalence is lower than that of the other MCA anomalies. The prevalence of accessory MCA was reported to range from $0.3 \%$ to $2.7 \%$ on autopsy reports and $0.24 \%$ to $3.1 \%$ on angiography. ${ }^{32,33}$ The prevalence of duplicated MCA is about $0.7 \%$ to $2.9 \%$ on autopsy reports and $1.5 \%$ on angiography. ${ }^{33}$ Fenestrated MCA prevalence is approximately $0.17 \%$ to $1 \%$ on angiographic studies. , $11,23,31^{2}$

\section{Epidemiology}

There has been no study on the epidemiology of rete MCA anomalies. However, most articles about rete MCA were published in Asian countries. In a pooled analysis including our cases, only 3 of 60 patients were not Asians if we assume that patients in Turkey are Asian nationals (Tables 1 and 2). ${ }^{7,22,34}$ Of course, we need accurate data investigation, but we believe that the rete MCA anomaly is more prevalent in Asians, as is moyamoya disease. In the future, research on the epidemiology of this anomaly is needed.

\section{Pathogenesis (Congenital Versus Acquired)}

The pathogenesis of rete MCA is not well known yet. Many authors described rete MCA as a congenital anomaly resulting from a fusion interference of the main trunk of the MCA in the embryonic development stage 1,3,15,22,25,26 $^{2}$ (Fig. 4). During normal embryonic development of the human intracranial arterial system, the distal primitive ICA initially divides into a large branch, which becomes the anterior choroidal artery and numerous plexiform arterial twigs, which evolve into the primitive ACA and MCA. ${ }^{20}$ Later, this primitive MCA coalesces into a single main trunk by fusion and regression. ${ }^{20}$ Interruption by unexplained causes during the coalescing period results in a plexiform arterial network appearance. ${ }^{3}$ Rete MCA is the persistence of the fetal arterial network of rete that normally coalesces into the definitive MCA. ${ }^{6}$

However, it is not reasonable to define rete MCA as a congenital anomaly. There is no concrete evidence that rete MCA is not an acquired anomaly. An alternative explanation of rete MCA is that it is a response to arterial occlusion or stenosis. Shin et al. argued that rete MCA anomalies were not an acquired disease because they were identified at a relatively young age (average age 41 years), and patients had neither obvious atherosclerotic degeneration nor leptomeningeal collaterals on cerebral angiography. ${ }^{26}$

In a pooled analysis including our cases, patients were not relatively young (average age 51.2 years). Furthermore, the whitish vessel of the rete MCA anomalies found in our operative cases was different from the usual atherosclerotic stenoocclusive vessel. We believe that the stump observed in the surgical field and the vessel connected to it in our case 9 may reduce the likelihood of it being an acquired lesion (Fig. 3D). Therefore, we assume that a rete MCA anomaly may be a congenital variation rather than an acquired lesion secondary to atherosclerotic degeneration. 

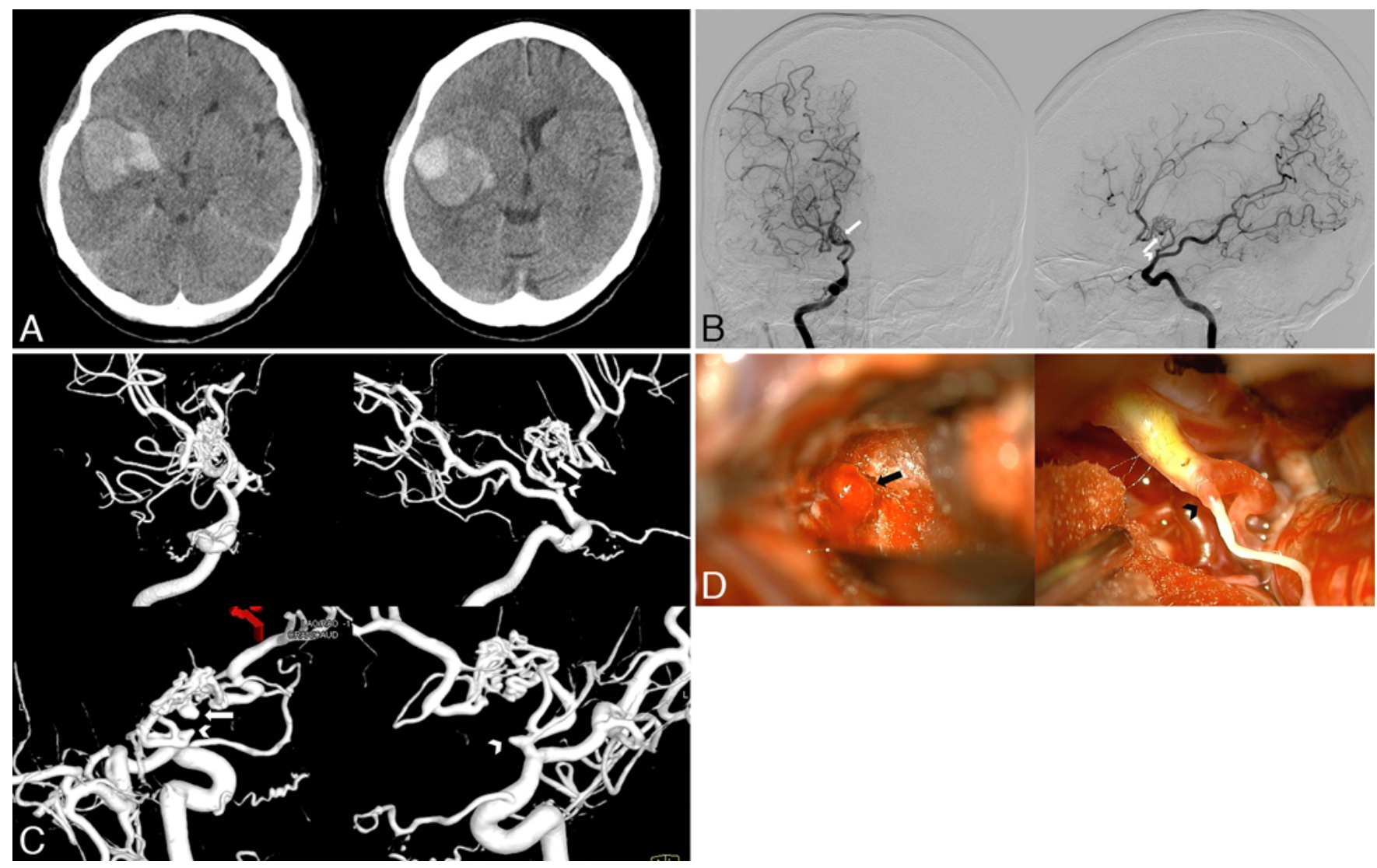

FIG. 3. Case 9. A: Initial brain CT reveals ICH on the right temporal lobe. B: DSA reveals an $M_{1}$ anomaly, but the distal MCA segments are intact in caliber, and the distal MCA is patent. Two regions suspected of an aneurysm are represented by an arrow and an arrowhead. C: On 3D rotational angiography, a weblike rete MCA anomaly is noted on the right $\mathrm{M}_{1}$ segment, and two aneurysms are observed (arrows). One aneurysm inside the rete is suspected to be bleeding (arrowheads). Another is seen on the right proximal ACA. D: Surgical exploration reveals a white, cordlike rudimentary rete MCA vessel (arrow). One aneurysm was clipped, and the hematoma beside the aneurysm was evacuated (arrowhead). The other one was not an aneurysm but a stump that was linked to the vessel, which no longer had flow and was similar to a thin, white straw. Figure is available in color online only.

\section{Clinical Presentation}

Clinically, rete MCA anomalies are able to present as either a hemorrhagic or ischemic stroke. In a pooled analysis including our study (Tables 1 and 2), 32 patients $(53.3 \%)$ presented with hemorrhagic stroke. Eleven patients $(18.3 \%)$ presented with ischemic stroke, including TIA. Seventeen cases (28.3\%) were identified incidentally. In only 3 cases, hemorrhagic stroke occurred during the course of observation. In 1 case, the patient was initially observed with no treatment and subsequently suffered subcortical hemorrhage and subdural hematoma. ${ }^{9}$ In another case, a patient without any symptoms was discharged and readmitted with TIA. Two years after the initial admission, the patient was hospitalized with an SAH. ${ }^{30}$ In another case, the patient initially had an asymptomatic MCA anomaly, but ICH occurred after 39 months of follow-up. ${ }^{25}$

Previous papers primarily reported hemorrhagic stroke cases. Recently, however, there have been more reports of ischemic stroke and incidentally identified cases. The increase of patients with ischemic stroke and incidental findings may be caused by the development of better diagnostic tools. The advances of DSA have contributed to the identification of rete MCA anomalies. If rete MCA anomalies are suspected on MR angiography or CT angiography, DSA must be performed.

In cases of cerebral hemorrhage, surgical treatment should be considered by determining whether an accompanying aneurysm is present. An aneurysm located inside the rete is likely to be the cause of bleeding and must be treated. An aneurysm located outside the rete may not be the bleeding focus, but it should be observed closely. Additionally, it should be noted that hemorrhagic stroke including SAH can occur without an accompanying aneurysm. In 32 patients who presented with hemorrhagic stroke, 6 patients had rete MCA anomalies not associated with an aneurysm, including 1 of our cases..$^{1,25,29}$ Three cases have been reported with SAH not associated with ruptured cerebral aneurysms. ${ }^{1,25,29}$

The progress of patients with rete MCA anomalies presenting with TIA or mild symptomatic acute infarction can be observed without surgical treatment. To our knowledge, there was no malignant MCA infarction. We assumed this was because the distal MCA flow was maintained by the weblike rete vessels instead of the normal, single MCA.

Seven patients had ICH without aneurysms. . $, 9,25,30$ In these cases, it is unclear whether ICH was related to the 
TABLE 2. Published cases of rete MCA anomalies and associated with aneurysm

\begin{tabular}{|c|c|c|c|c|c|c|c|c|c|}
\hline \multirow[b]{2}{*}{ Authors \& Year } & \multirow{2}{*}{$\begin{array}{l}\text { Pt } \\
\text { No. }\end{array}$} & \multirow{2}{*}{$\begin{array}{l}\text { Sex, Age } \\
\quad \text { (yrs) }\end{array}$} & \multirow[b]{2}{*}{ Nationality } & \multirow[b]{2}{*}{ Presentation } & \multirow{2}{*}{$\begin{array}{c}\text { Rete } \\
\text { MCA } \\
\text { Site }\end{array}$} & \multicolumn{3}{|c|}{ Aneurysm } & \multirow[b]{2}{*}{ Treatment } \\
\hline & & & & & & No. & Location & Site & \\
\hline Yaşargil et al., 1976 & 1 & M, 38 & Swiss & $\mathrm{SAH}$ & Rt & 1 & $\mathrm{ACOA}$ & $\mathrm{Rt}$ & Clipping \\
\hline Tanaka et al., 1980 & 2 & $\mathrm{M}, 40$ & Japan & SAH, IVH & $\mathrm{Lt}$ & 1 & PCA & $\mathrm{Lt}$ & Clipping \\
\hline Fukawa et al., 1982 & 3 & $F, 53$ & Japan & $\mathrm{SAH}$ & $\mathrm{Lt}$ & 1 & Pcho & $\mathrm{Lt}$ & Not available \\
\hline Matsuda et al., 1983 & 4 & $\mathrm{~F}, 51$ & Japan & IVH & $\mathrm{Lt}$ & 2 & $\begin{array}{l}\text { PLcho } \\
\text { ICA }\end{array}$ & $\begin{array}{l}\mathrm{Lt} \\
\mathrm{Rt}\end{array}$ & $\begin{array}{l}\text { Trapping, EMS } \\
\text { Conservative }\end{array}$ \\
\hline Nakazawa et al., 1985 & 5 & $M, 48$ & Japan & $\mathrm{SAH}, \mathrm{ICH}$ & Lt & 1 & ACA & $\mathrm{Lt}$ & Clipping \\
\hline Grabel et al., 1989 & 6 & $\mathrm{M}, 60$ & USA & $\mathrm{ICH}$ & $\mathrm{Lt}$ & 1 & $M_{1}$ & $\mathrm{Lt}$ & Conservative \\
\hline Kageji et al., 1992 & 7 & M, 23 & Japan & $\mathrm{SAH}$ & Rt & 1 & MCA & $\mathrm{Lt}$ & Clipping \\
\hline Han et al., 1994 & 8 & $F, 34$ & Korea & $\mathrm{SAH}$ & Lt & 1 & ACA & $\mathrm{Lt}$ & Clipping \\
\hline Inoue et al., 1994 & 9 & M, 59 & Japan & $\mathrm{SAH}$ & Rt & 1 & ACA & $\mathrm{Rt}$ & Clipping \\
\hline Amagasaki et al., 1998 & 10 & $M, 64$ & Japan & Incidental (unconsciousness) & $\mathrm{Lt}$ & 1 & $\mathrm{~A}_{2}$ & $\mathrm{Lt}$ & Clipping \\
\hline Seki et al., 2001 & 11 & $\mathrm{~F}, 63$ & Japan & $\mathrm{ICH}, \mathrm{SAH}$ & $\mathrm{Lt}$ & 2 & $\begin{array}{l}A_{1} \\
P_{2}\end{array}$ & $\begin{array}{l}\text { Lt } \\
\text { Lt }\end{array}$ & $\begin{array}{l}\text { Clipping } \\
\text { Trapping }\end{array}$ \\
\hline Park et al., 2004 & 12 & $\mathrm{~F}, 74$ & Korea & $\mathrm{ICH}, \mathrm{SAH}$ & Rt & 2 & $\begin{array}{l}M_{1} \\
M_{1}\end{array}$ & $\begin{array}{l}\mathrm{Rt} \\
\mathrm{Rt}\end{array}$ & $\begin{array}{l}\text { Clipping } \\
\text { Clipping }\end{array}$ \\
\hline Kim et al., 2005 & 13 & $\mathrm{~F}, 64$ & Korea & $\mathrm{SAH}$ & $\mathrm{Lt}$ & 2 & $\begin{array}{l}\mathrm{A}_{1} \\
\mathrm{ACOA}\end{array}$ & $\begin{array}{l}\mathrm{Lt} \\
\mathrm{Lt}\end{array}$ & $\begin{array}{l}\text { Clipping } \\
\text { Clipping }\end{array}$ \\
\hline Liu et al., 2005 & $\begin{array}{l}14 \\
15\end{array}$ & $\begin{array}{r}\mathrm{M}, 44 \\
\mathrm{~F}, 67\end{array}$ & Taiwan & $\begin{array}{l}\mathrm{ICH}, \mathrm{SAH} \\
\mathrm{ICH}, \mathrm{SAH}\end{array}$ & $\begin{array}{l}\mathrm{Lt} \\
\mathrm{Lt}\end{array}$ & $\begin{array}{l}1 \\
1\end{array}$ & $\begin{array}{l}M_{1} \\
M_{1}\end{array}$ & $\begin{array}{l}\mathrm{Lt} \\
\mathrm{Lt}\end{array}$ & $\begin{array}{l}\text { Clipping } \\
\text { Clipping }\end{array}$ \\
\hline Cekirge et al., 2005 & 16 & M, 32 & Turkey & SAH, IVH & Lt & 1 & $A_{1}$ & $\mathrm{Lt}$ & Coiling \\
\hline Narisawa et al., 2009 & 17 & $\mathrm{M}, 83$ & Japan & $\mathrm{ICH}$ & Lt & 1 & MCA & $\mathrm{Lt}$ & Trapping \\
\hline $\begin{array}{l}\text { Rodríguez-Hernández } \\
\text { et al., } 2011\end{array}$ & 18 & $M, 52$ & USA & $\mathrm{ICH}$ & Rt & 1 & $\mathrm{M}_{1}$ & Rt & Trapping (failed bypass) \\
\hline \multirow[t]{15}{*}{ Seo et al., 2012} & 19 & $\mathrm{~F}, 49$ & Korea & $\mathrm{ICH}$ & $\mathrm{Lt}$ & 1 & SHA & $\mathrm{Rt}$ & Burr hole, coiling, EDAS \\
\hline & 20 & $\mathrm{~F}, 10$ & & Acute infarction & $\mathrm{Lt}$ & - & - & - & EDAS \\
\hline & 21 & $\mathrm{~F}, 72$ & & Change from incidental to $\mathrm{ICH}$ & Rt & - & - & - & Burr hole \\
\hline & 22 & $M, 58$ & & Incidental & $\mathrm{Lt}$ & 2 & $\begin{array}{l}\text { SHA } \\
\text { SHA }\end{array}$ & $\begin{array}{l}\mathrm{Lt} \\
\mathrm{Rt}\end{array}$ & $\begin{array}{l}\text { Conservative } \\
\text { Coiling }\end{array}$ \\
\hline & 23 & M, 58 & & Incidental & $\mathrm{Lt}$ & - & - & - & Conservative \\
\hline & 24 & $\mathrm{~F}, 45$ & & $\mathrm{ICH}$ & $\mathrm{Lt}$ & - & - & - & Conservative \\
\hline & 25 & $F, 56$ & & Acute infarction & Rt & - & - & - & Conservative \\
\hline & 26 & M, 73 & & $\mathrm{SAH}$ & Rt & 1 & MCA & $\mathrm{Rt}$ & Clipping \\
\hline & 27 & $\mathrm{~F}, 51$ & & Acute infarction & $\mathrm{Lt}$ & - & - & - & Conservative \\
\hline & 28 & $F, 58$ & & Acute infarction & Rt & 1 & ICA & $\mathrm{Lt}$ & Conservative \\
\hline & 29 & $M, 73$ & & $\mathrm{SAH}$ & $\mathrm{Lt}$ & 1 & ICA & $\mathrm{Rt}$ & Conservative \\
\hline & 30 & $\mathrm{M}, 61$ & & Incidental & $\mathrm{Lt}$ & - & - & - & Conservative \\
\hline & 31 & M, 38 & & Incidental & $\mathrm{Lt}$ & - & - & - & Conservative \\
\hline & 32 & $\mathrm{M}, 74$ & & $\mathrm{ICH}$ & $\mathrm{Lt}$ & - & - & - & Conservative \\
\hline & 33 & $F, 56$ & & Acute infarction & Rt & - & - & - & Conservative \\
\hline \multirow[t]{4}{*}{ Shin et al., 2014} & 34 & M, 42 & Korea & $\mathrm{SAH}, \mathrm{ICH}, \mathrm{IVH}$ & $\mathrm{Lt}$ & 2 & $\begin{array}{l}M_{1} \\
M_{1}\end{array}$ & $\begin{array}{l}\mathrm{Lt} \\
\mathrm{Lt}\end{array}$ & $\begin{array}{l}\text { Trapping } \\
\text { Clipping }\end{array}$ \\
\hline & 35 & $\mathrm{~F}, 49$ & & $\mathrm{SAH}, \mathrm{ICH}, \mathrm{IVH}$ & $\mathrm{Lt}$ & 1 & $M_{1}$ & $\mathrm{Lt}$ & Clipping \\
\hline & 36 & $F, 46$ & & $\mathrm{SAH}, \mathrm{ICH}, \mathrm{IVH}$ & $\mathrm{Lt}$ & 2 & $\begin{array}{l}M_{1} \\
A_{1}\end{array}$ & $\begin{array}{l}\mathrm{Lt} \\
\mathrm{Lt}\end{array}$ & $\begin{array}{l}\text { Gluing (failed) } \\
\text { Clipping }\end{array}$ \\
\hline & 37 & M, 26 & & SAH, IVH & Rt & 1 & PLcho & $\mathrm{Rt}$ & Observation \\
\hline
\end{tabular}


TABLE 2. Published cases of rete MCA anomalies and associated with aneurysm

\begin{tabular}{|c|c|c|c|c|c|c|c|c|c|}
\hline \multirow[b]{2}{*}{ Authors \& Year } & \multirow{2}{*}{$\begin{array}{l}\text { Pt } \\
\text { No. }\end{array}$} & \multirow{2}{*}{$\begin{array}{l}\text { Sex, Age } \\
\text { (yrs) }\end{array}$} & \multirow[b]{2}{*}{ Nationality } & \multirow[b]{2}{*}{ Presentation } & \multirow{2}{*}{$\begin{array}{c}\text { Rete } \\
\text { MCA } \\
\text { Site }\end{array}$} & \multicolumn{3}{|c|}{ Aneurysm } & \multirow[b]{2}{*}{ Treatment } \\
\hline & & & & & & No. & Location & Site & \\
\hline \multirow[t]{6}{*}{ Akkan et al., 2015} & 38 & $M, 54$ & Turkey & Incidental (vertigo) & Rt & 1 & ICA & $\mathrm{Lt}$ & Conservative \\
\hline & 39 & $\mathrm{M}, 43$ & & Incidental (traumatic SAH) & Rt & - & - & - & Conservative \\
\hline & 40 & $F, 53$ & & Incidental (headache) & Rt & - & - & - & Conservative \\
\hline & 41 & $\mathrm{~F}, 37$ & & Incidental (vertigo) & Rt & - & - & - & Conservative \\
\hline & 42 & $\mathrm{M}, 44$ & & $\mathrm{ICH}$ & $\mathrm{Lt}$ & - & - & - & Conservative \\
\hline & 43 & $\mathrm{~F}, 40$ & & Incidental (headache, vertigo) & $\mathrm{Lt}$ & - & - & - & Conservative \\
\hline Uchiyama et al., 2016 & 44 & $F, 52$ & Japan & $\begin{array}{l}\text { Change from incidental, to TIA, } \\
\text { to } \mathrm{SAH}, \mathrm{ICH}\end{array}$ & $\mathrm{Lt}$ & - & - & - & Conservative \\
\hline \multirow[t]{2}{*}{ Tashiro et al., 2016} & 45 & $F, 76$ & Japan & SAH & Lt & - & - & - & Conservative \\
\hline & 46 & $\mathrm{~F}, 81$ & & $\mathrm{SAH}$ & Lt & - & - & - & Conservative \\
\hline Inoue et al., 2016 & 47 & M, 55 & Japan & Change from incidental to $\mathrm{ICH}$ & $\mathrm{Lt}$ & - & - & - & Bypass \\
\hline
\end{tabular}

EDAS = encephaloduroarteriosynangiosis; $\mathrm{EMS}=$ encephalomyosynangiosis; $\mathrm{PCA}=$ posterior cerebral artery; Pcho = posterior choroidal artery; PLcho = posterolateral choroidal artery; $\mathrm{Pt}=$ patient; $\mathrm{SHA}=$ superior hypophyseal artery.

rete MCA anomaly. It could be simply a hypertensive ICH. However, it is assumed that the hemodynamic stress caused by the small plexiform MCA vessel had an effect.

\section{Associated Aneurysm Formation}

The most commonly found vessel abnormality associated with the rete MCA anomaly is arterial aneurysm. Forty aneurysms were found in 31 patients (51.7\%). Twentyfour were ruptured aneurysms ipsilateral to the rete MCA, and only 1 was a ruptured aneurysm contralateral to the rete MCA. The remaining 15 were unruptured aneurysms: 8 were on the ipsilateral side and 7 were contralateral to the rete MCA.

Hemodynamic stress is considered to be the main cause of aneurysm formation. ${ }^{15,26}$ Liu et al. believe that the rete MCA, the fetal arterial network, is usually thinner and the muscular layer less developed..$^{15}$ Therefore, vessels that are fragile and less elastic than the normal adult MCA are vulnerable to pressure from the ICA. As a result, flow-related aneurysms can be more easily formed.

Interestingly, we misdiagnosed a stump as an aneurysm in a single case (case 9). Like this case, aneurysms diagnosed by DSA may not be real aneurysms. In this case, surgical clipping and endovascular treatment such as coiling may be unnecessary.

\section{Differential Diagnosis}

Several diseases need to be identified. The major differential diagnoses we have to make are moyamoya disease, degenerative atherosclerotic stenoocclusive disease, and rete mirabile anomaly. Additionally, radiation therapy, neurofibromatosis type 1, Down's syndrome, sickle cell disease, and even autoimmune diseases may develop a striate collateral network of the proximal MCA with a weblike pattern. ${ }^{1}$

\section{Moyamoya Disease and Moyamoya Syndrome}

Moyamoya disease is a progressive stenoocclusive vasculopathy affecting the ICA bifurcation and its major branches, with secondary formation of an anastomotic collateral network at the base of the brain (moyamoya vessels) and transdural collaterals from the external carotid artery (ECA). With progression, involvement includes the proximal MCAs and ACAs and on rare occasions the posterior circulation. While typical moyamoya disease is angiographically bilateral and symmetric, rete MCA is a unilateral anomaly. Additionally, in rete MCA anomalies, there are no transdural collateral vessels as are seen in most cases of moyamoya disease. In moyamoya disease, distal MCA vessels have the appearance of a "puff of smoke" (described as moyamoya in Japanese). However, in

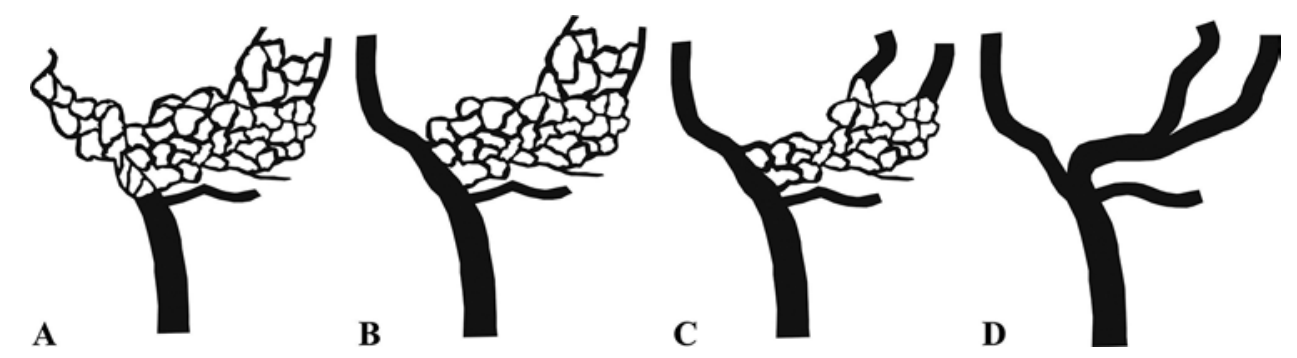

FIG. 4. Embryonic development of the MCA. A: Fetal type. The distal primitive ICA is divided into a large branch and numerous plexiform arterial networks. B: The primitive ACA is formed, but the primitive MCA has not yet formed. C: Rete MCA. Interruption by an unexplained cause during the coalescing period results in the persistence of the fetal arterial network except the distal MCA. D: Adult-type MCA. 
TABLE 3. Angiographic differences among diseases showing abnormal MCA

\begin{tabular}{llll}
\hline & \multicolumn{1}{c}{ Rete MCA Anomaly } & \multicolumn{1}{c}{ Moyamoya Disease } & \multicolumn{1}{c}{ Stenoocclusive Disease } \\
\hline Affected site & Exclusively MCA M & $\begin{array}{c}\text { Usually ICA terminus, possibly MCA, } \\
\text { ACA, or PCA }\end{array}$ & $\begin{array}{c}\text { MCA M }_{1} \text {, possibly multiple other intracranial } \\
\text { vessels }\end{array}$ \\
\hline Appearance & Weblike, w/ multiple channels & Atresic, w/ prominent basal collaterals & Tapered, thin, or similar to a bird's beak \\
\hline Laterality & Exclusively unilateral & Usually bilateral, possibly unilateral & Unilateral, possibly bilateral \\
\hline Distal MCA flow & Normal & Scanty, puff of smoke appearance & Normal \\
\hline Transdural collaterals & None & Frequent & None \\
\hline Progression & None & Rapid & Slow \\
\hline
\end{tabular}

rete MCA anomaly, the caliber of the distal MCA and flow are maintained. This is the most important difference from moyamoya disease. In this respect, a rete MCA anomaly can also be distinguished from unilateral moyamoya syndrome.

Even regarding prevalence, rete MCA anomaly is different from moyamoya disease. Whereas moyamoya disease had a prevalence of up to $0.016 \%,{ }^{13}$ rete MCA anomaly had a relatively high prevalence rate of $0.11 \%$ to approximately $1.17 \% .^{15,25}$

\section{Rete Mirabile}

Rete mirabile is an anomaly that should be identified. A rete mirabile (Latin for "wonderful net") is a complex arterial network that is found in a number of vertebrates in which the ECA, especially branches of the maxillary artery, takes over the blood supply from the ICAs. Mikami et al. described six characteristic angiographic features of rete mirabile: 1) hypoplasia of the ICA beginning from the carotid bifurcation; 2) an arterial plexus between the internal maxillary artery and the cavernous portion of the ICA; 3) dilation of the ophthalmic artery and anastomosis from the internal maxillary artery; 4) the supraclinoid ICA is not hypoplastic and is fed by the arterial plexus and ophthalmic artery; 5) bilateral lesions; and 6) no moyamoya vessels or anastomosing vessels in the intradural portion. ${ }^{17}$ Because rete MCA anomalies have no definite transdural collateral vessels and are unilateral, they can be distinguished from rete mirabile.

\section{Degenerative Stenoocclusive Disease}

Another related anomaly is degenerative stenoocclusive disease of the MCA. This disease is an acquired progressive disease secondary to atherosclerotic degenerative vessel changes. It is truly difficult to prove that rete MCA is not an acquired anomaly. However, rete MCA anomalies can be distinguished from atheromatous disease, as there is no evidence of atheromatous plaque or stenosis in other cerebral arteries. ${ }^{5}$ A summary table distinguishes rete MCA anomaly from the other entities (Table 3).

\section{Treatment}

There has been little research on rete MCA anomalies and few treatments are known. Therefore, the optimal treatment modality has not been established. In many cases, regardless of whether or not the aneurysm was a cause of bleeding, the aneurysms were treated with clipping. Another treatment modality for aneurysms is trap- ping, which can be applied if the vessels are judged to be weak. Bypass surgery was mainly used for patients with hemorrhagic stroke. To our knowledge, there have been no cases of bypass surgery in patients with ischemic stroke, except 1 case in our study. More research into rete MCA anomalies is needed, including treatment modalities.

As observed in a few cases, there may be intracranial hemorrhage without an aneurysm associated with the rete MCA anomaly. Therefore, patients who are suspected of having rete MCA anomalies are advised to undergo DSA. Additionally, even if the aneurysm is treated, a de novo aneurysm associated with a rete MCA anomaly can occur later because it is believed to be caused by hemodynamic stress.

This study is limited by its retrospective design and small sample size. Additionally, pathological evaluation of the rete MCA was not performed. However, despite these limitations, our study showed radiological and clinical features of the rete MCA anomaly through various cases and a review of the literature.

\section{Conclusions}

Vascular practitioners need to recognize the normal anatomy of the basal arteries of the brain as well as their variations. Although uncommon, clinicians should understand the clinical and radiological features of patients with rete MCA to avoid misdiagnosis and unnecessary treatments. This unfamiliar type of vascular lesion of the MCA appears to be associated with the occurrence of an aneurysm, which is an important clinical aspect. It should be differentiated from other vascular diseases, and patients presenting incidentally should be carefully monitored for vulnerability to both hemorrhagic and ischemic strokes.

\section{Acknowledgments}

We thank Ryun Hee Hong for her assistance during this study.

\section{References}

1. Akkan K, Ucar M, Kilic K, Celtikci E, Ilgit E, Onal B: Unfused or twig-like middle cerebral artery. Eur J Radiol 84:2013-2018, 2015

2. Amagasaki K, Yagishita T, Kawataki T, Kase M, Nukui H: Middle cerebral artery aplasia associated with an aneurysm of the proximal anterior cerebral artery. Acta Neurochir (Wien) 140:1313-1314, 1998

3. Cekirge HS, Peynircioglu B, Saatci I: Endovascular treatment of an "anterior cerebral artery" aneurysm in a patient with 
"embryonic unfused middle cerebral artery" anomaly: a case report. Neuroradiology 47:690-694, 2005

4. Crompton MR: The pathology of ruptured middle-cerebral aneurysms with special reference to the differences between the sexes. Lancet 2:421-425, 1962

5. Fukawa O, Aihara H, Wakasa H: [Middle cerebral artery occlusion with moyamoya phenomenon.-2nd report: report of an autopsy case.] No Shinkei Geka 10:1303-1310, 1982 (Jpn)

6. Gailloud P, Albayram S, Fasel JH, Beauchamp NJ, Murphy $\mathrm{KJ}$ : Angiographic and embryologic considerations in five cases of middle cerebral artery fenestration. AJNR Am J Neuroradiol 23:585-587, 2002

7. Grabel JC, Levine M, Hollis P, Ragland R: Moyamoya-like disease associated with a lenticulostriate region aneurysm. Case report. J Neurosurg 70:802-803, 1989

8. Han DH, Gwak HS, Chung CK: Aneurysm at the origin of accessory middle cerebral artery associated with middle cerebral artery aplasia: case report. Surg Neurol 42:388-391, 1994

9. Inoue A, Kohno K, Fukumoto S, Ichikawa H, Onoue S, Miyazaki H, et al: [A case of ECA-MCA double anastomoses for hemorrhagic type of twig-like MCA.] No Shinkei Geka 44:463-471, 2016 (Jpn)

10. Inoue R, Katayama S, Kasai N, Hori S: [Middle cerebral artery occlusion with unilateral moyamoya like vessels and with ruptured anterior cerebral artery aneurysm-its relation to the antiphospholipid antibody syndrome.] No To Shinkei 46:995-998, 1994 (Jpn)

11. Ito J, Maeda H, Inoue K, Onishi Y: Fenestration of the middle cerebral artery. Neuroradiology 13:37-39, 1977

12. Kageji T, Murayama Y, Matsumoto K: [Spontaneous middle cerebral artery occlusion with moyamoya-like vessels associated with contralateral middle cerebral artery aneurysm; a case report.] No Shinkei Geka 20:177-181, 1992 (Jpn)

13. Kim JS: Moyamoya disease: epidemiology, clinical features, and diagnosis. J Stroke 18:2-11, 2016

14. Kim MS, Oh CW, Hur JW, Lee JW, Lee HK: Aneurysms located at the proximal anterior cerebral artery and anterior communicating artery associated with middle cerebral artery aplasia: case report. Surg Neurol 64:534-537, 2005

15. Liu HM, Lai DM, Tu YK, Wang YH: Aneurysms in twig-like middle cerebral artery. Cerebrovasc Dis 20:1-5, 2005

16. Matsuda M, Handa J, Saito A, Matsuda I, Kamijyo Y: Ruptured cerebral aneurysms associated with arterial occlusion. Surg Neurol 20:4-12, 1983

17. Mikami T, Takahashi A, Houkin K: Carotid rete mirabile associated with subarachnoid hemorrhage. Neurol Med Chir (Tokyo) 45:201-204, 2005

18. Nakazawa T, Suzuki F, Miyamoto Y, Matsuda M: [Aplasia of the proximal middle cerebral artery associated with an aneurysm of the proximal anterior cerebral artery. Case report.] Nihon Geka Hokan 54:521-525, 1985 (Jpn)

19. Narisawa A, Takahashi T, Saito R, Sato K, Endo H, Noshita $\mathrm{N}$, et al: [A case of repeated intracerebral hemorrhage due to a ruptured aneurysm of collateral circulation from the posterior cerebral artery to the middle cerebral artery.] No Shinkei Geka 37:787-792, 2009 (Jpn)

20. Padget D: The development of the cranial arteries in the human embryo. Contr Embryol Carneg Instn 32:205-261, 1948

21. Park J, Hwang JH, Hamm IS: Aneurysm rupture at an anomalous collateral artery that extended from the proximal $\mathrm{A}_{2}$ segment to the middle of the $\mathrm{M}_{1}$ segment, bypassing atresia of the internal carotid artery bifurcation. Case report. J Neurosurg 100:332-334, 2004

22. Rodríguez-Hernández A, Lu DC, Miric S, Lawton MT: Aneurysms associated with non-moyamoya collateral arterial networks: report of three cases and review of literature. Neurosurg Rev 34:517-522, 2011
23. Sanders WP, Sorek PA, Mehta BA: Fenestration of intracranial arteries with special attention to associated aneurysms and other anomalies. AJNR Am J Neuroradiol 14:675-680, 1993

24. Seki Y, Fujita M, Mizutani N, Kimura M, Suzuki Y: Spontaneous middle cerebral artery occlusion leading to moyamoya phenomenon and aneurysm formation on collateral arteries. Surg Neurol 55:58-62, 2001

25. Seo BS, Lee YS, Lee HG, Lee JH, Ryu KY, Kang DG: Clinical and radiological features of patients with aplastic or twiglike middle cerebral arteries. Neurosurgery 70:1472-1480, 2012

26. Shin HS, Lee SH, Ryu CW, Koh JS: Flow-related intracranial aneurysms associated with unfused arterial twigs relevant to different vascular anomalies: embryologic and hemodynamic considerations. Acta Neurochir (Wien) 156:1637-1646, 2014

27. Takahashi M, Fujimoto T, Suzuki R, Asai J, Miyo T, Hokaku $\mathrm{H}$ : [A case of spontaneous middle cerebral artery occlusion associated with a cerebral aneurysm angiographically disappearing after STA-MCA anastomosis.] No Shinkei Geka 25:727-732, 1997 (Jpn)

28. Tanaka Y, Takeuchi K, Akai K: Intracranial ruptured aneurysm accompanying moyamoya phenomenon. Acta Neurochir (Wien) 52:35-43, 1980

29. Tashiro R, Inoue T, Shibahara I, Ezura M, Uenohara H, Fujimura M, et al: Nonaneurysmal subarachnoid hemorrhage due to unfused or twiglike middle cerebral artery rupture: two case reports. J Stroke Cerebrovasc Dis 25:e77-e78, 2016

30. Uchiyama T, Okamoto H, Koguchi M, Tajima Y, Suzuyama $\mathrm{K}$ : [A case of aplastic or twig-like middle cerebral artery presenting with an intracranial hemorrhage two years after a transient ischemic attack.] No Shinkei Geka 44:143-148, 2016 (Jpn)

31. Umansky F, Dujovny M, Ausman JI, Diaz FG, Mirchandani HG: Anomalies and variations of the middle cerebral artery: a microanatomical study. Neurosurgery 22:1023-1027, 1988

32. Watanabe T, Tago M, Shibuya S, Yoshida Y, Amo H: [The accessory middle cerebral artery (author's transl).] No Shinkei Geka 3:31-35, 1975 (Jpn)

33. Yamamoto H, Marubayashi T, Soejima T, Matsuoka S, Matsukado Y, Ushio Y: Accessory middle cerebral artery and duplication of middle cerebral artery-terminology, incidence, vascular etiology, and developmental significance. Neurol Med Chir (Tokyo) 32:262-267, 1992

34. Yaşargil MG, Smith RD: Association of middle cerebral artery anomalies with saccular aneurysms and moyamoya disease. Surg Neurol 6:39-43, 1976

\section{Disclosures}

The authors report no conflict of interest concerning the materials or methods used in this study or the findings specified in this paper.

\section{Author Contributions}

Conception and design: YB Kim. Acquisition of data: Cho, JJ Kim, Jang, Hong, Joo. Analysis and interpretation of data: Cho. Drafting the article: Cho. Critically revising the article: Cho. Reviewed submitted version of manuscript: Cho. Study supervision: YB Kim.

\section{Correspondence}

Yong Bae Kim: College of Medicine, Yonsei University, Gangnam Severance Hospital, Seoul, Korea. ybkim69@yuhs.ac. 